\title{
Temporalis: an open source software for dynamic LCA
}

DOI: $10.21105 /$ joss.00612

\section{Software}

- Review ¿

- Repository e

- Archive c

Submitted: 06 March 2018 Published: 17 April 2018

\section{Licence}

Authors of papers retain copyright and release the work under a Creative Commons Attribution 4.0 lnternational License (CC-BY).

\section{Giuseppe Cardellini ${ }^{1}$ and Chris Mutel $^{2}$}

$1 \mathrm{KU}$ Leuven 2 Paul Scherrer Institut

\section{Summary}

Temporalis (Cardellini and Mutel 2018) is an open source software for dynamic Life Cycle Assessment (LCA) calculations in Python. It is built on top of the advanced life cycle assessment framework Brightway2 (C. Mutel 2017) and allows to perform dynamic LCA and take into account time in both inventory and impact assessment. It makes use of graph traversal and convolution to solve the inventory and makes it possible to use several types of impact assessment methods, both static and dynamic. Specifically, Temporalis can resolve time-explicit Life Cycle Inventory (LCI), handle both absolute and relative temporal distributions, as well as exchanges with databases that have no temporal information. It can also perform static and dynamic characterization of emissions (including both distribution over time and characterization as a function of time); can calculated impact for any time horizon and correctly account for the impact of biogenic carbon fluxes (i.e. it does not assume any carbon neutrality and considers of the climate impact due to forest regrowth). The importance of considering time in LCA has been already already shown in the past ("Considering Time in LCA: Dynamic LCA and Its Application to Global Warming Impact Assessments" 2010,Kendall (2012), Reap et al. (2008)). Some experimental dynamic LCA methodologies have been proposed in the literature (Collinge et al. 2013,Tiruta-Barna et al. (2016),Beloin-Saint-Pierre, Heijungs, and Blanc (2014),Beloin-Saint-Pierre et al. (2017)), but a software tool which allows the LCA practitioners to easily perform dynamic LCA was still lacking. Temporalis has been already used for LCA analysis of the FP7 project FORMIT ("FORMIT Fp7 Project" n.d.) and scientific articles (Giuseppe et al. accepted), with other articles under preparation. Documentation, tutorials and usages can be found on Temporalis repository.

\section{References}

Beloin-Saint-Pierre, Didier, Reinout Heijungs, and Isabelle Blanc. 2014. "The ESPA (Enhanced Structural Path Analysis) Method: A Solution to an Implementation Challenge for Dynamic Life Cycle Assessment Studies." The International Journal of Life Cycle Assessment 19 (4):861-71. https://doi.org/10.1007/s11367-014-0710-9.

Beloin-Saint-Pierre, Didier, Annie Levasseur, Manuele Margni, and Isabelle Blanc. 2017. "Implementing a Dynamic Life Cycle Assessment Methodology with a Case Study on Domestic Hot Water Production." Journal of Industrial Ecology 21 (5):1128-38. https: //doi.org/10.1111/jiec.12499.

Cardellini, Giuseppe, and Christopher Mutel. 2018. "Temporalis." 2018. https:// bitbucket.org/cardosan/brightway2-temporalis.

Collinge, William O., Amy E. Landis, Alex K. Jones, Laura A. Schaefer, and Melissa M. Bilec. 2013. "Dynamic Life Cycle Assessment: Framework and Application to an Institutional Building." The International Journal of Life Cycle Assessment 18 (3):53852. https://doi.org/10.1007/s11367-012-0528-2. 
"Considering Time in LCA: Dynamic LCA and Its Application to Global Warming Impact Assessments." 2010. Environmental Science \& Technology 44 (8). American Chemical Society (ACS):3169-74. https://doi.org/10.1021/es9030003.

"FORMIT Fp7 Project." n.d. Accessed March 5, 2018. https://cordis.europa.eu/project/ rcn/104508_en.html.

Giuseppe, Cardellini, Valada Tatiana, Cornillier Claire, Vial Estelle, Dragoi Marian, Goudiaby Venceslas, Mues Volker, et al. accepted. "EFO-Lci: A New Life Cycle Inventory Database of Forestry Operations in Europe." Environmental Management. https: //doi.org/10.1007/s00267-018-1024-7.

Kendall, Alissa. 2012. "Time-Adjusted Global Warming Potentials for LCA and Carbon Footprints." The International Journal of Life Cycle Assessment 17 (8):1042-9. https: //doi.org/10.1007/s11367-012-0436-5.

Mutel, Chris. 2017. "Brightway: An Open Source Framework for Life Cycle Assessment." The Journal of Open Source Software 2 (12). The Open Journal:236. https://doi.org/10. 21105 /joss.00236.

Reap, John, Felipe Roman, Scott Duncan, and Bert Bras. 2008. "A Survey of Unresolved Problems in Life Cycle Assessment." The International Journal of Life Cycle Assessment 13 (5). Springer Nature:374-88. https://doi.org/10.1007/s11367-008-0009-9.

Tiruta-Barna, Ligia, Yoann Pigné, Tomás Navarrete Gutiérrez, and Enrico Benetto. 2016. "Framework and Computational Tool for the Consideration of Time Dependency in Life Cycle Inventory: Proof of Concept." Journal of Cleaner Production 116 (March):198-206. https://doi.org/10.1016/j.jclepro.2015.12.049. 